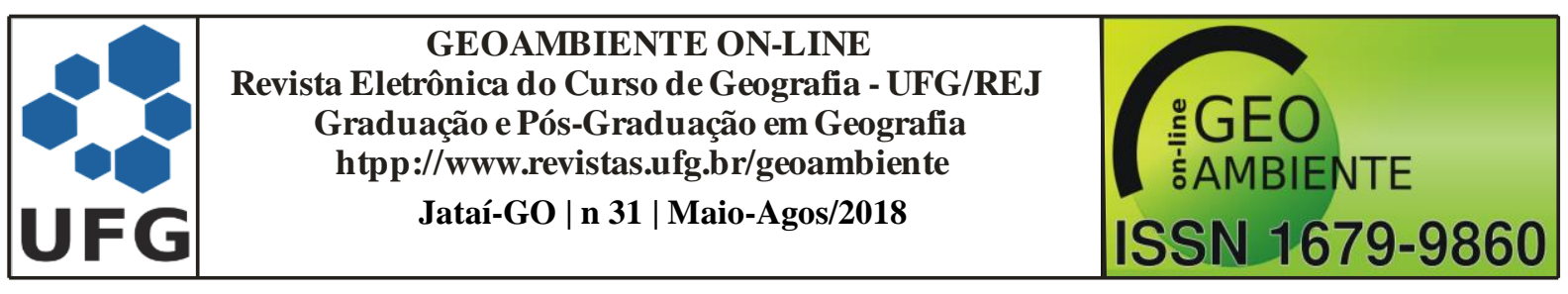

\title{
QUALIDADE MICROBIOLÓGICA DA ÁGUA DO ARROIO CLARIMUNDO, NOROESTE DO ESTADO DO RIO GRANDE DO SUL, BRASIL
}

\author{
Maurício Kasper' ${ }^{1}$, Daniel Joner Daroit ${ }^{2}$ \\ (1 - Universidade Federal da Fronteira Sul, Biólogo, kasper.mauricio.rural@gmail.com, 2 - \\ Universidade Federal da Fronteira Sul, Docente, djdaroit@gmail.com)
}

Resumo: Recursos hídricos urbanos podem ser deteriorados pela descarga de esgotos domésticos. Considerando que alguns grupos bacterianos são utilizados como indicadores da qualidade da água, este estudo avaliou a qualidade microbiológica das águas do arroio Clarimundo (Cerro Largo/RS) nas quatro estações do ano de 2016. Coliformes totais e termotolerantes foram determinados pelo método dos tubos múltiplos e bactérias heterotróficas utilizando contagem em placas, em águas amostradas próximo à nascente (P1), antes do arroio atravessar o maior adensamento populacional da cidade (P2) e após área urbana (P3). Densidades médias de coliformes totais foram de 2.715 Número Mais Provável (NMP)/100 mL no P1, 6.800 NMP/100 mL no P2, e 166.500 NMP/100 mL no P3. Para coliformes termotolerantes, nos pontos P1, P2 e P3 foram observadas densidades médias de 693, 3.455 e $62.250 \mathrm{NMP} / 100 \mathrm{~mL}$, respectivamente. Contagens de heterotróficos foram maiores no P3, alcançando média de 149.000 Unidades Formadoras de Colônia (UFC)/mL, em comparação àquelas em P1 (2.960 UFC/mL) e P2 (6.770 UFC/mL). As densidades de coliformes e heterotróficos indicam a contaminação da água por matéria orgânica, inclusive de origem fecal, oriunda de atividades antrópicas. A implementação de sistemas eficientes para coleta e tratamento de esgotos pode beneficiar a qualidade das águas deste arroio.

Palavras-chave: Qualidade da água. Contaminação. Bactérias coliformes.

\section{MICROBIOLOGICAL QUALITY OF THE CLARIMUNDO STREAM WATER, NORTHWEST OF RIO GRANDE DO SUL STATE, BRAZIL}




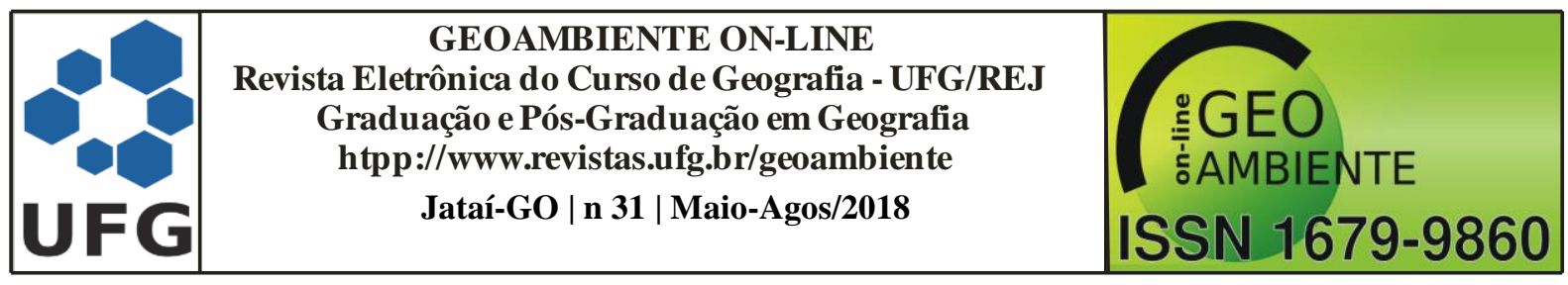

Abstract: Urban water resources might be depreciated by domestic sewage discharges. Urban water resources might be depreciated by domestic sewage discharges. Considering that some bacterial groups are utilized as water quality indicators, this study evaluated the microbiological water quality of the Clarimundo stream (Cerro Largo county, Rio Grande do Sul State, Brazil) during the four seasons of the year 2016. Total and thermotolerant coliforms were determined through the multiple-tube method and heterotrophic bacteria using plate counts, on waters sampled near the stream spring $(\mathrm{P} 1)$, before the stream cross the greater population density of the city (P2), and after the urban area (P3). Average densities of total coliforms were 2,715 Most Probable Number (MPN)/100 mL at P1, 6,800 MPN/100 mL at P2, and 166,500 MPN/100 mL at P3. Regarding thermotolerant coliforms, at P1, P2 and P3 the observed average densities were 693, 3,455 and 62,250 MPN/100 mL, respectively. Counts of heterotrophic bacteria were higher at P3, reaching an average of 149,000 Colony Forming Units $(\mathrm{CFU}) / \mathrm{mL}$ in comparison to averages at P1 $(2,960 \mathrm{CFU} / \mathrm{mL})$ and P2 $(6,770$ $\mathrm{CFU} / \mathrm{mL}$ ). Densities of coliforms and heterotrophic bacteria indicate water contamination with organic matter, including fecal material, originated from anthropic activities. The implementation of efficient systems for sewage collecting and treatment might benefit this stream water quality.

Keywords: Water quality. Contamination. Coliform bacteria.

\section{CALIDAD MICROBIOLÓGICA DEL AGUA DEL ARROYO CLARIMUNDO, NOROESTE DEL ESTADO DE RIO GRANDE DO SUL, BRASIL}

Resumen: Recursos hídricos urbanos pueden deteriorarse por la descarga de aguas residuales domésticas. Considerando que algunos grupos bacterianos se utilizan como indicadores de calidad del agua, este estudio evaluó la calidad microbiológica de las aguas del arroyo Clarimundo (Cerro Largo/RS) en las cuatro estaciones del año 2016. Coliformes totales y termotolerantes se determinaron mediante tubos múltiples y bacterias heterotróficas mediante recuento en placas, en aguas muestreadas cerca de la naciente (P1), antes del arroyo atravesar la mayor densificación poblacional de la ciudad (P2) y después del área urbana (P3). Promedios de coliformes totales fueron 2.715 Número Más Probable (NMP)/100 mL en P1, 6.800 NMP/100 mL en P2, y 166.500 NMP/100 mL en P3. Para coliformes termotolerantes, 


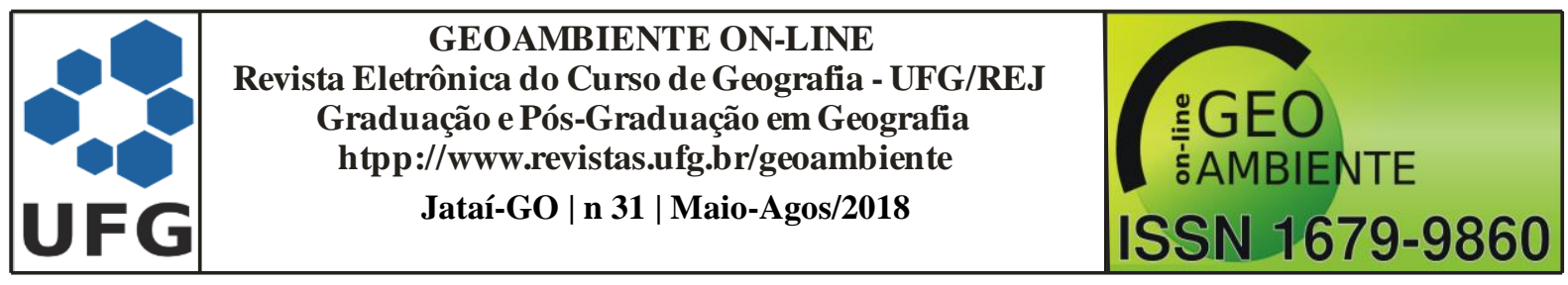

en P1, P2 y P3 los promedios fueron 693, 3.455 y 62.250 NMP/100 mL, respectivamente. Conteos de heterotróficos fueron mayores en P3, alcanzando promedio de 149.000 Unidades Formadoras de Colonia (UFC)/mL, en comparación con P1 (2.960 UFC/mL) y P2 (6.770 UFC/mL). Densidades de coliformes y heterotróficos indican contaminación del agua por materia orgánica, incluso de origen fecal, oriunda de actividades antrópicas. La implementación de sistemas eficientes de recolección y tratamiento de aguas residuales puede beneficiar la calidad del agua del arroyo.

Palabras clave: Calidad del agua. Contaminación. Bacterias coliformes.

\section{Introdução}

A água é componente integral do planeta Terra e recurso renovável básico à vida, atuando de forma crucial na dinâmica dos ciclos biogeoquímicos nos ecossistemas. Considerando a água doce como recurso fundamental, as águas superficiais, subterrâneas e reservas de água são componentes estratégicos e essenciais sob as perspectivas da qualidade de vida da população humana, do desenvolvimento econômico e da sustentabilidade ambiental (SOUZA et al., 2014; TUNDISI, 2014).

A qualidade da água depende, dentre outros fatores, do comportamento dos ecossistemas terrestres e aquáticos, e das ações antrópicas. O crescimento populacional e os padrões de desenvolvimento humano aumentam a demanda por água ao mesmo tempo em que causam alterações sobre os recursos hídricos. De fato, a qualidade da água vem sendo modificada especialmente pela multiplicidade e complexidade dos usos da água pelo homem (MAROTTA et al., 2008).

Em ambientes urbanos, um dos principais problemas relacionados à qualidade da água é sua contaminação por esgotos domésticos. Cerca de $80 \%$ da água retirada de mananciais para abastecimento urbano retornam aos mananciais na forma de efluentes sanitários e esgoto doméstico (BRASIL, 2006). Neste sentido, aproximadamente $43 \%$ do esgoto gerado e $74 \%$ do esgoto coletado passam por tratamento, indicando que enormes volumes de esgotos brutos atingem sem tratamento os corpos d'água (BRASIL, 2017).

O esgoto doméstico, composto por águas usadas para higiene pessoal, cocção e lavagem de alimentos e utensílios, bem como pela água utilizada em vasos sanitários, pode 


\begin{tabular}{|c|c|c|}
\hline & $\begin{array}{c}\text { GEOAMBIENTE ON-LINE } \\
\text { Revista Eletrônica do Curso de Geografia - UFG/REJ } \\
\text { Graduação e Pós-Graduação em Geografia } \\
\text { htpp://www.revistas.ufg.br/geoambiente } \\
\text { Jataí-Go | n 31 | Maio-Agos/2018 }\end{array}$ & $\begin{array}{c}\text { : GEO } \\
\text { JEAMBIENTE } \\
\text { G }\end{array}$ \\
\hline
\end{tabular}

conter (micro)organismos patogênicos (PEREIRA, 2004). Dentre estes patógenos estão aqueles de origem fecal, comuns causadores de infecções intestinais. Logo, o despejo de dejetos humanos sem tratamento prévio pode resultar na contaminação dos corpos hídricos com patógenos que podem ser veiculados através do consumo e/ou contato com estas águas (RAZZOLINI \& GUNTHER, 2008).

A identificação de patógenos em águas é usualmente complexa e de elevado custo. Assim, são utilizados microrganismos indicadores, valendo-se da interpretação de que sua presença pode assinalar o contato da água com material fecal e, portanto, indicar o potencial risco da presença de patógenos (SOUZA et al., 2014). Tipicamente, são utilizados como indicadores microrganismos encontrados em grande concentração nas fezes humanas, especialmente bactérias pertencentes ao grupo coliforme (VASCONCELOS et al., 2006).

Os coliformes totais são indicadores da presença de vários gêneros de bactérias de diferentes origens na água, enquanto que os coliformes termotolerantes compreendem bactérias que usualmente indicam contaminação por fezes de animais de sangue quente, incluindo o homem (OLIVEIRA FILHO et al., 2012). Desta forma, o grupo dos coliformes termotolerantes vem sendo empregado como indicador de poluição de águas naturais e do grau de interferência humana (SIQUEIRA et al., 2012; VALLE JÚNIOR et al., 2013; ANDRADE et al., 2015). Ainda, a qualidade microbiológica de um corpo d'água pode ser aferida utilizando indicadores complementares, como a densidade de bactérias heterotróficas (ARAUJO et al., 2015).

O município de Cerro Largo localiza-se no extremo noroeste do Estado do Rio Grande do Sul (RS). Segundo o Censo 2010, este município possui 13.289 habitantes, sendo que $79,5 \%$ da população reside na zona urbana (IBGE, 2016). A área do município de Cerro Largo está inserida em duas bacias hidrográficas, a dos rios Turvo-Santa Rosa-Santo Cristo (43,23\% da área na bacia) e a do Rio Ijuí (56,77\% da área na bacia) (RIO GRANDE DO SUL, 2012a).

O arroio Clarimundo, pertencente à Bacia Hidrográfica do Rio Ijuí, possui extensão de aproximadamente $4 \mathrm{~km}$, toda ela na área do município de Cerro Largo e apresenta, como uma de suas características, o fato de cerca de $70 \%$ de seu curso perpassar a área urbana de Cerro Largo (DIEL et al., 2015; Figura 1). Atividades de monitoramento podem fornecer 


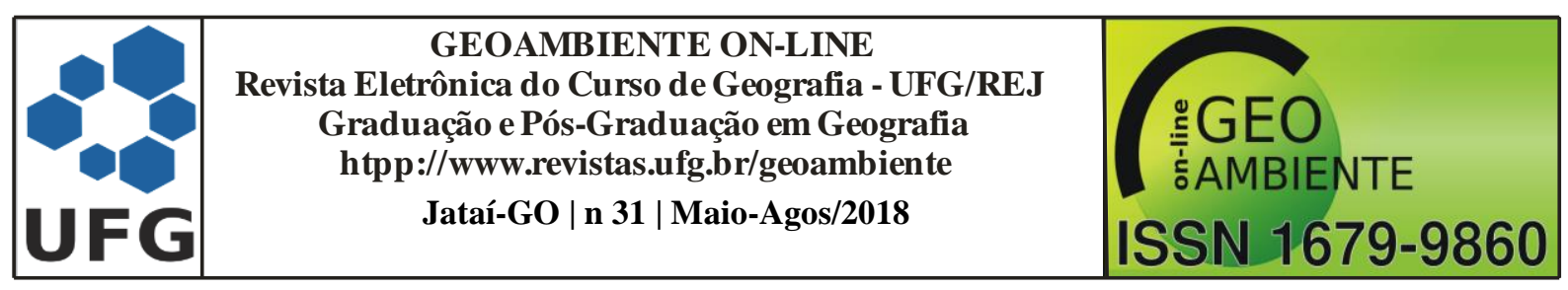

informações acerca da contaminação de recursos hídricos e potenciais implicações relativas à saúde pública e ambiental (MAROTTA et al., 2008).

Figura 1: O arroio Clarimundo como parte da Bacia Hidrográfica do Rio Ijuí. (A) Localização da Bacia Hidrográfica do Rio Ijuí no Estado do Rio Grande do Sul, indicada pelo asterisco; (B) Área urbana de Cerro Largo inserida na Bacia Hidrográfica do Rio Ijuí; (C) Localização aproximada dos pontos de amostragem de água no arroio Clarimundo, em Cerro Largo/RS.

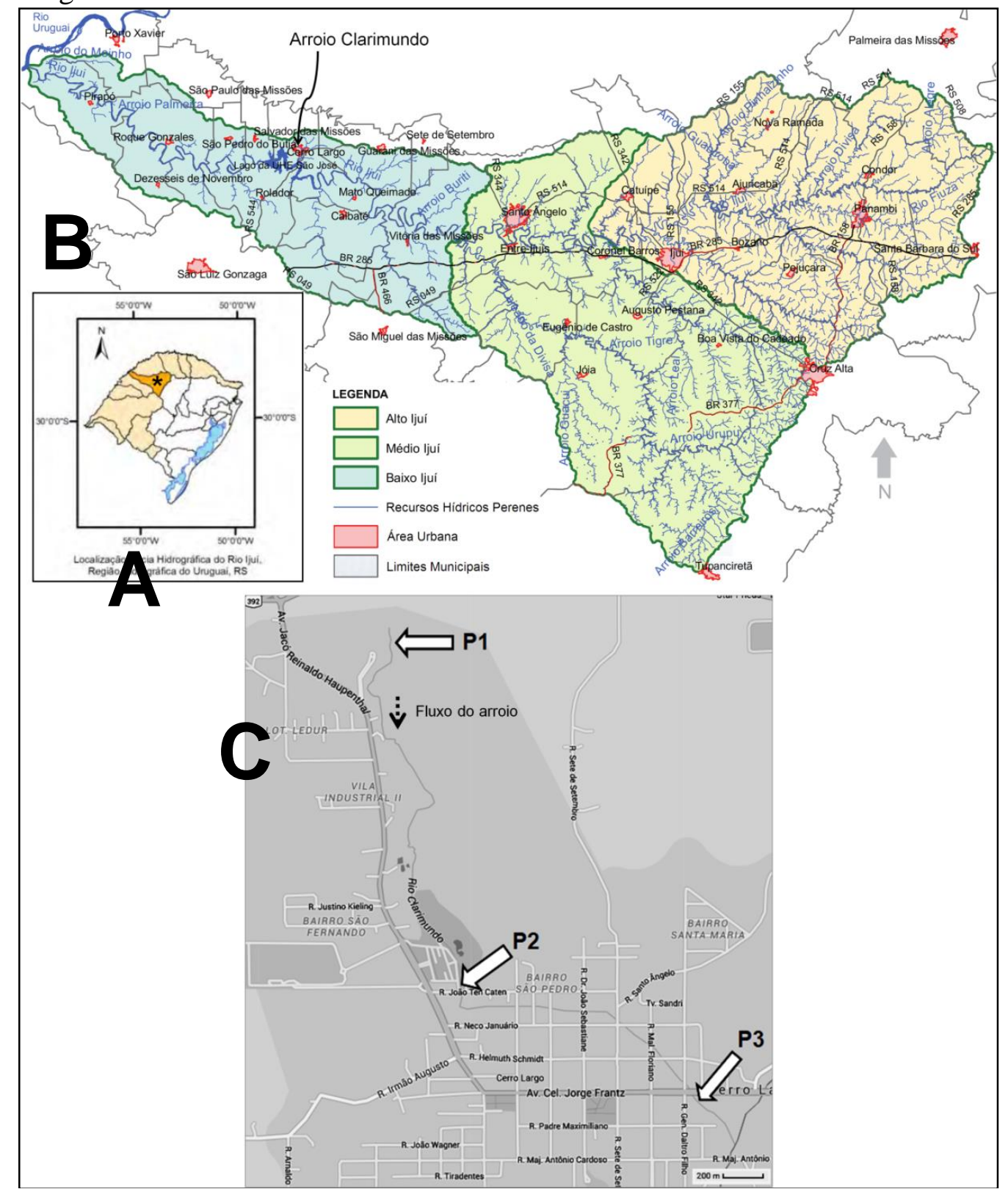

Fonte: (A) Adaptada de Rio Grande do Sul (2012a); (B) Adaptada de Rio Grande do Sul (2012b); (C) Adaptada de Google Maps (2018). 


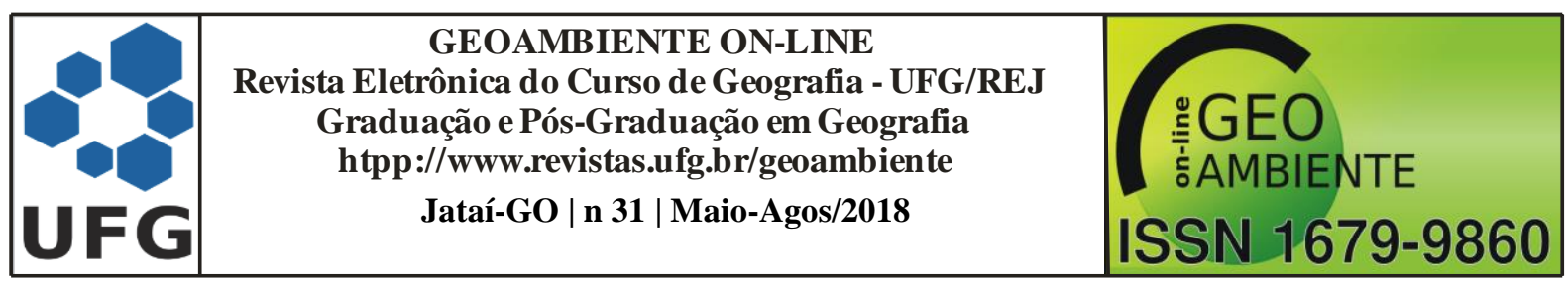

Considerando a especial relevância dos esgotos domésticos como poluidores de águas superficiais que perpassam áreas residenciais de ambientes urbanos, bem como o papel destes dejetos como carreadores de potenciais microrganismos patogênicos, este estudo avaliou a qualidade microbiológica das águas do arroio Clarimundo em período que contemplou as quatro estações do ano de 2016.

\section{Material e métodos}

Amostras de água

As amostras foram coletadas utilizando recipientes de vidro estéreis, em três pontos do curso do arroio Clarimundo (Cerro Largo/RS). O ponto 1 (P1; 28 07'33.81''S, e $54^{\circ} 44^{\prime} 56.90^{\prime}$ 'O) correspondeu a área próxima à nascente, que apresenta mata ciliar relativamente conservada e baixo adensamento residencial em sua proximidade (DIEL et al., 2015). O ponto 2 (P2; $28^{\circ} 08^{\prime} 33.24^{\prime}$ 'S , e $\left.54^{\circ} 44^{\prime} 43.31^{\prime \prime} \mathrm{O}\right)$, anterior ao arroio perpassar a parte de maior adensamento populacional da cidade e com mata ciliar comprometida, situou-se a aproximadamente $2,1 \mathrm{~km}$ à jusante do $\mathrm{P} 1$. O ponto $3\left(\mathrm{P} 3 ; 2^{\circ} 08^{\prime} 50.20^{\prime}\right.$ ' $\mathrm{S}$, e $54^{\circ} 44^{\prime} 00.28^{\prime}$ ' $\left.\mathrm{O}\right)$, após a passagem do arroio pela área urbana e a aproximadamente 1,4 km à jusante do P2, possui mata ciliar reduzida (Figura 1C).

Cada ponto foi amostrado quatro vezes durante o ano de 2016. Particularmente, a $1^{\text {a }}$ coleta ocorreu em 29/02, a $2^{\text {a }}$ coleta em 09/05, a $3^{\text {a }}$ coleta em 01/08 e a $4^{\text {a }}$ coleta em 07/11, correspondendo às estações de verão, outono, inverno e primavera, respectivamente. Após as coletas, os recipientes foram conduzidos sob refrigeração ao laboratório.

\section{Determinação de coliformes totais e termotolerantes}

As amostras foram submetidas a diluições decimais seriadas em salina peptonada $(8,5$ $\mathrm{g} / \mathrm{L} \mathrm{NaCl}, 1 \mathrm{~g} / \mathrm{L}$ peptona) estéril. As análises de coliformes foram realizadas pela técnica de fermentação em tubos múltiplos, utilizando testes de presunção e confirmação. Para os testes presuntivos de coliformes, volumes de $1 \mathrm{~mL}$ das amostras coletadas ou das diluições foram utilizados para inocular três séries de três tubos contendo $10 \mathrm{~mL}$ de Caldo Lauril Triptose (HiMedia, India) e um tubo de Durham invertido. Após incubação $\left(36{ }^{\circ} \mathrm{C}, 24-48\right.$ h), os tubos foram observados quanto à produção de gás ou efervescência do caldo sob gentil agitação. 


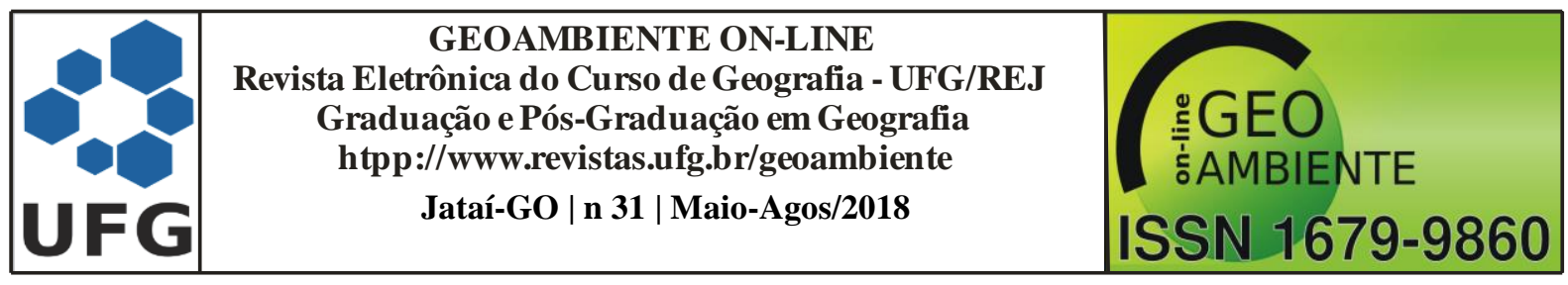

Os tubos positivos no teste presuntivo foram utilizados para inocular, utilizando alça de platina estéril, tubos contendo $10 \mathrm{~mL}$ de Caldo Verde Brilhante Bile 2\% (Himedia, India) para a confirmação de coliformes totais, e tubos contendo $10 \mathrm{~mL}$ de Caldo EC (Himedia, India) para confirmação de coliformes termotolerantes. Em ambos os casos, os tubos continham um tubo de Durham invertido para captação de gás. Após as inoculações, tubos com Caldo Verde Brilhante Bile $2 \%$ foram incubados a $36{ }^{\circ} \mathrm{C}$ por $24-48 \mathrm{~h}$ em estufa, enquanto que tubos com Caldo EC foram incubados a $44,5^{\circ} \mathrm{C}$ por $24-48 \mathrm{~h}$ em banho-maria. Seguindo-se as respectivas incubações, a positividade para os grupos de coliformes foi confirmada pela formação de gás ou efervescência do meio de cultura quando agitado gentilmente (SALVATORI et al., 2013).

\section{Contagem de bactérias heterotróficas totais}

Diluições decimais das amostras de água $(1 \mathrm{~mL})$ foram distribuídas em placas de Petri estéreis e, em seguida, foi vertido Ágar Padrão para Contagem (PCA; Himedia, India) fundente $\left(45-48{ }^{\circ} \mathrm{C}\right)$. As placas foram gentilmente agitadas para homogeneização da amostra e, após solidificação do meio, foram incubadas a $36{ }^{\circ} \mathrm{C}$ por 48 h. Seguindo-se a incubação, foi realizada a contagem das colônias bacterianas. Levando-se em conta o fator de diluição, os resultados foram apresentados como Unidades Formadoras de Colônia (UFC)/mL.

\section{Pluviosidade e temperatura atmosférica}

Os dados de pluviosidade $(\mathrm{mm})$ e temperatura atmosférica $\left({ }^{\circ} \mathrm{C}\right)$, durante o período do estudo, foram coletados por estação automática localizada no município de Cerro Largo/RS.

\section{Análise dos resultados}

A partir do número de tubos positivos em cada um dos testes de confirmação de coliformes, e considerando as diluições empregadas, o Número Mais Provável (NMP) para coliformes totais e para coliformes termotolerantes foi determinado conforme tabela estatística com limites de confiança de 95\% (BLODGETT, 2002), sendo os resultados expressos como NMP/100 mL. 


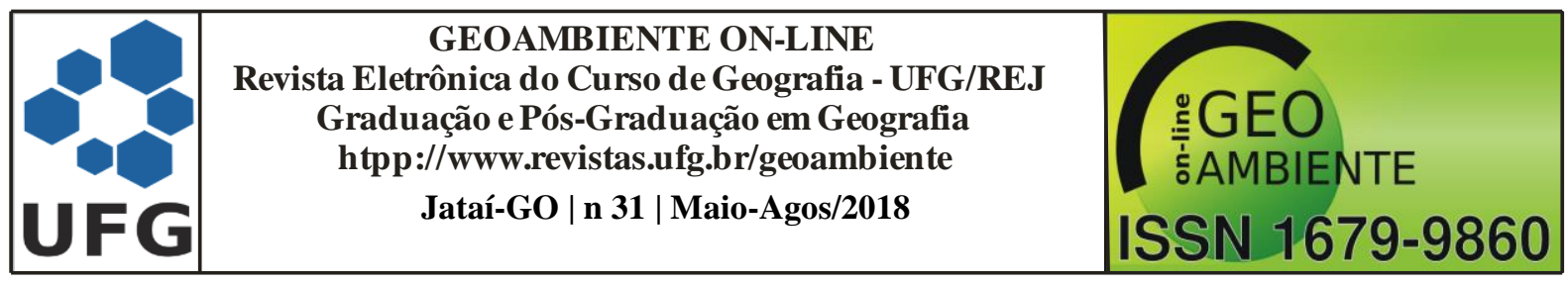

Os resultados das contagens de bactérias heterotróficas (UFC/mL) foram utilizados para cálculo de médias, submetidas à análise de variância e comparadas pelo teste de Tukey, considerando-se nível de significância de $5 \%$.

\section{Resultados e discussão}

A qualidade da água pode ser retratada por diversos parâmetros e, dentre aqueles que são diretamente influenciados pelo uso do solo na bacia de drenagem, podem ser destacados a densidade de coliformes totais e termotolerantes (MAROTTA et al., 2008). No arroio Clarimundo, o número de coliformes totais aumentou conforme a ordem espacial dos pontos amostrados, sendo os menores valores detectados no P1 na $3^{\text {a }}$ coleta e os maiores detectados no P3 durante a $1^{\mathrm{a}}$ e $2^{\mathrm{a}}$ coletas (Tabela 1$)$.

Tabela 1: Número Mais Provável de coliformes totais nas águas do arroio Clarimundo (Cerro Largo/RS), em diferentes coletas realizadas em três pontos de amostragem no ano de 2016.

\begin{tabular}{cccc}
\hline \multirow{2}{*}{ Coleta } & \multicolumn{3}{c}{ Coliformes totais (NMP/100 $\mathbf{~ m L )}$} \\
\cline { 2 - 4 } & $\mathrm{P} 1$ & $\mathrm{P} 2$ & $\mathrm{P} 3$ \\
\hline $1^{\mathrm{a}}$ coleta $(29 / 02)$ & 1.500 & 9.300 & 240.000 \\
$2^{\mathrm{a}}$ coleta $(09 / 05)$ & 1.500 & 9.300 & 240.000 \\
$3^{\mathrm{a}}$ coleta $(01 / 08)$ & 360 & 4.300 & 93.000 \\
$4^{\mathrm{a}}$ coleta $(07 / 11)$ & 7.500 & 4.300 & 93.000 \\
\hline NMP calculado a partir de tabela estatística com limites de confiança de $95 \%$.
\end{tabular}

Este comportamento tendeu a se repetir em todas as coletas realizadas, com exceção da $4^{\mathrm{a}}$ coleta, quando as menores densidades de coliformes totais foram observadas no P2, e não no P1. A densidade de coliformes totais foi pelo menos 12,4 vezes maior no P3 em comparação ao P1 (4 ${ }^{\text {a }}$ coleta), enquanto nas outras coletas os valores no P3 foram 160-258 vezes maiores que no $\mathrm{P} 1$.

Quanto ao P2, a densidade de coliformes totais foi aproximadamente 20 vezes menor neste ponto em comparação com P3. As densidades médias de coliformes totais, considerando os quatro períodos amostrais, atingiram 2.715 NMP/100 mL no P1, $6.800 \mathrm{NMP} / 100 \mathrm{~mL}$ no $\mathrm{P} 2$, e 165.500 NMP/100 mL no P3. Coliformes totais podem representar bactérias associadas 


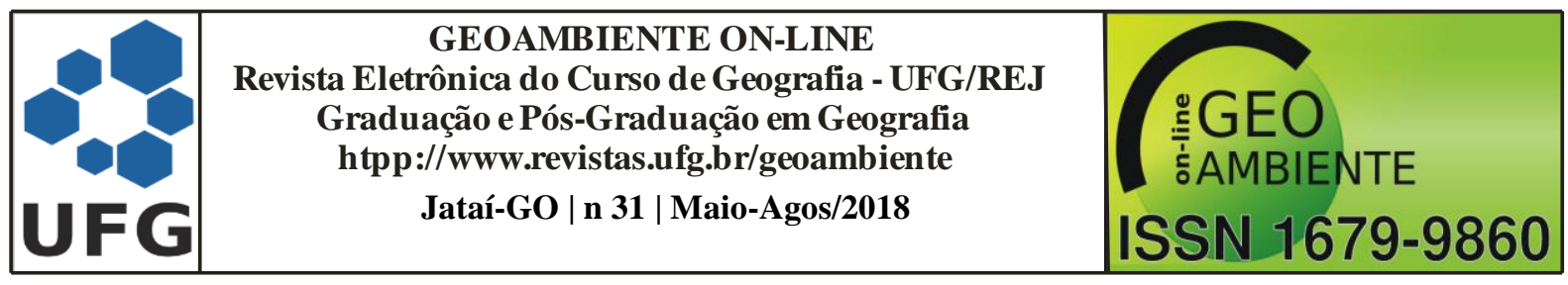

à poluição por esgotos domésticos, mas também bactérias passíveis de participação em processos de depuração orgânica no corpo hídrico (GIATTI et al., 2004).

$\mathrm{Na} 4^{\mathrm{a}}$ coleta, a maior densidade de coliformes totais no $\mathrm{P} 1$ em relação ao $\mathrm{P} 2$ pode indicar o carreamento de bactérias deste grupo a partir dos arredores da nascente para o corpo hídrico, por exemplo, através de escoamento superficial (ALESSIO et al., 2009). Neste contexto, atividades agropecuárias são realizadas em áreas próximas.

Quanto aos coliformes termotolerantes (Tabela 2), constatou-se que, independentemente da estação do ano em que ocorreu a amostragem, os índices destes microrganismos foram maiores no $\mathrm{P} 3$, ou seja, após o centro urbano, quando comparadas às densidades no $\mathrm{P} 1$, em área próxima à nascente. As menores densidades foram detectadas no $\mathrm{P} 1$ na $3^{\mathrm{a}}$ coleta e, as maiores, obervadas no P3 durante a $1^{\mathrm{a}}$ coleta.

A densidade de coliformes termotolerantes foi pelo menos 10 vezes maior no P3 em comparação ao P1 (4 $4^{\text {a }}$ coleta). Nas outras coletas realizadas, a densidade deste grupo de microrganismos no P3 foi pelo menos 250 vezes maior do que o mensurado no P1. Para o P2, as densidades de coliformes termotolerantes foram de 5 a 20 vezes menores do que o constatado no P3. As densidades médias de coliformes termotolerantes, considerando os quatro períodos amostrais, atingiram 693 NMP/100 mL no P1, 3.455 NMP/100 mL no P2, e 62.250 NMP/100 mL no P3.

Tabela 2: Número Mais Provável de coliformes termotolerantes nas águas do arroio Clarimundo (Cerro Largo/RS) em diferentes coletas realizadas em três pontos de amostragem no ano de 2016.

\begin{tabular}{cccc}
\hline \multirow{2}{*}{ Coleta } & \multicolumn{3}{c}{ Coliformes termotolerantes (NMP/100 $\mathbf{~ m L})$} \\
\cline { 2 - 4 } & $\mathrm{P} 1$ & $\mathrm{P} 2$ & $\mathrm{P} 3$ \\
\hline $1^{\mathrm{a}}$ coleta $(29 / 02)$ & 150 & 4.300 & 110.000 \\
$2^{\mathrm{a}}$ coleta $(09 / 05)$ & 230 & 4.300 & 93.000 \\
$3^{\mathrm{a}}$ coleta $(01 / 08)$ & 92 & 920 & 23.000 \\
$4^{\mathrm{a}}$ coleta $(07 / 11)$ & 2.300 & 4.300 & 23.000 \\
\hline NMP calculado a partir de tabela estatística com limites de confiança de $95 \%$.
\end{tabular}

A Resolução No 357 do Conselho Nacional do Meio Ambiente (CONAMA), de 17 de março de 2005 (BRASIL, 2005), dispõe sobre a classificação dos corpos de água e estabelece, 


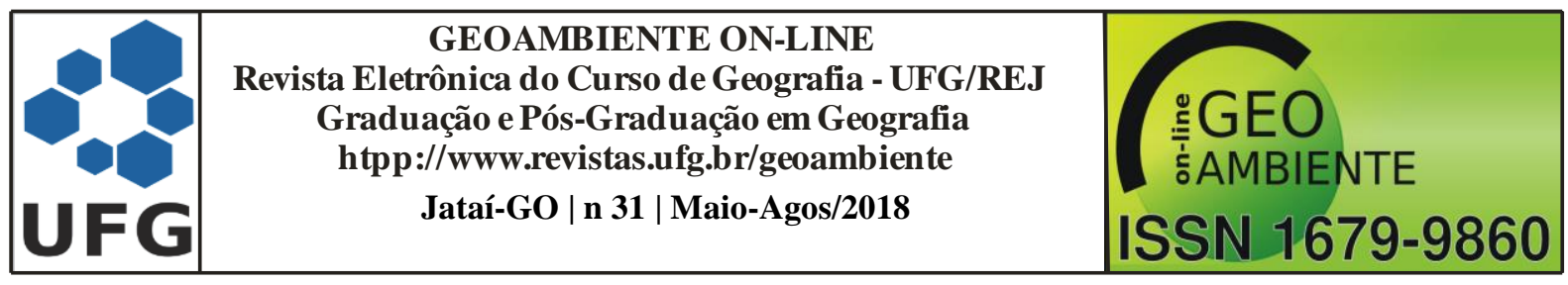

entre outros, limites de coliformes termotolerantes como um dos parâmetros para classificação das águas segundo a qualidade requerida para seus usos preponderantes.

Conforme as densidades de coliformes termotolerantes (Tabela 2), no P1 as águas do arroio Clarimundo corresponderam a Classe 1 na $1^{\mathrm{a}}$ e $3^{\mathrm{a}}$ coletas, Classe 2 na $2^{\mathrm{a}}$ coleta, e Classe 3 ou 4, dependendo da finalidade de uso da água, na $4^{\text {a }}$ coleta.

O P2 correspondeu a águas de Classe 2, 3 ou 4, dependendo da finalidade de uso e do período de coleta. O P3 correspondeu, em todas as análises, a águas de Classe 4. Já a Resolução CONAMA No 274, de 29 de novembro de 2000 (BRASIL, 2001), estabelece critérios de balneabilidade, classificando as águas como próprias ou impróprias para a recreação de contato primário. A partir das análises realizadas para coliformes termotolerantes (Tabela 2), as águas do arroio Clarimundo só seriam próprias para balneabilidade no P1, com exceção feita no período correspondente à $4^{\mathrm{a}}$ coleta neste ponto.

Os resultados indicam que a passagem do curso d'água pela área urbanizada, especialmente no $\mathrm{P} 3$, resultou em incremento da densidade de coliformes termotolerantes quando comparada àquelas observadas no P1 (Tabela 2). Contudo, cabe destacar que a elevada densidade de coliformes (totais e termotolerantes) no P1, especialmente na $4^{\text {a }}$ coleta, pode indicar o carreamento de microrganismos a partir de áreas adjacentes. A qualidade microbiológica vem sendo analisada em diversos cursos d'água situados em diferentes regiões brasileiras e, usualmente, os maiores índices de coliformes são reportados naqueles que perpassam áreas com características de ocupação urbana (GIATTI et al., 2004; CUNHA et al., 2010; ROCHA et al., 2010; OLIVEIRA FILHO et al., 2012; SOUZA et al., 2014).

Particularmente, Andrade e Felchak (2009) observaram que a quantidade de coliformes foi maior quanto mais à jusante do rio das Antas (Irati, PR), demonstrando que atividades urbanas influenciaram no aumento destes indicadores, especialmente o despejo de esgoto doméstico sem tratamento que ocorre por falta de saneamento, ligações incorretas de esgoto e falta de fiscalização.

Em amostras da água do Rio Piancó (PB), ponto de coleta próximo à nascente apresentou menores valores médios para coliformes totais e termotolerantes do que em ponto de coleta situado à jusante da área urbana do município de Pombal (PB), sendo esta elevação atribuída ao despejo de efluentes domésticos sem devido tratamento no corpo hídrico 


\begin{tabular}{|c|c|c|}
\hline & $\begin{array}{c}\text { GEOAMBIENTE ON-LINE } \\
\text { Revista Eletrônica do Curso de Geografia - UFG/REJ } \\
\text { Graduação e Pós-Graduação em Geografia } \\
\text { htpp://www.revistas.ufg.br/geoambiente } \\
\text { Jataí-Go | n 31 | Maio-Agos/2018 }\end{array}$ & $\begin{array}{c}\text { : GEO } \\
\text { G.AMBIENTE } \\
\text { G }\end{array}$ \\
\hline
\end{tabular}

(ANDRADE et al., 2015). A avaliação das águas do rio São Lourenço (São Lourenço, RS), realizada em três pontos de coleta, indicou que os maiores índices de coliformes totais e termotolerantes foram observados nos pontos onde o rio recebia esgoto doméstico (VASCONCELLOS et al., 2006).

Os coliformes termotolerantes, mesmo podendo não representar contaminação exclusivamente fecal, são importantes parâmetros para determinação da qualidade da água. A interpretação dos resultados obtidos para estes indicadores depende de informações complementares, que busquem estabelecer a origem e os fatores que contribuem para a contaminação do corpo d'água (VON SPERLING, 2014). Neste contexto, o município de Cerro Largo/RS não possui sistema adequado de esgotamento (DIEL et al., 2015). As soluções para os esgotos domésticos são individuais, consituindo-se por fossas sépticas, com a disposição final do esgoto no solo por meio de valas de infiltração e/ou sumidouros. Embora estas soluções reduzam o potencial poluidor, cargas remanescentes de esgoto podem ter o solo como corpo receptor, podendo atingir os recursos hídricos. No entanto, não há levantamento específico do número de sistemas individuais implantados no município e, ainda nesta perspectiva, há a possibilidade de sistemas incorretos e ligações clandestinas sem a implantação dos devidos sistemas de tratamento de efluentes.

O lançamento de dejetos residenciais em fossas sépticas ou fossas negras, usualmente sem filtros e sumidouros, podem levar à poluição do solo e da água através de percolação e escoamento superficial (OLIVEIRA FILHO et al., 2012). No caso das fossas, quando estas esgotam sua capacidade por falta de manutenção, ou em períodos chuvosos, o esgoto pode escoar pelas ruas e sistemas de drenagem pluvial para os rios próximos. Particularmente, o escoamento pluvial e os efluentes de esgotos em fossas estão entre as principais fontes difusas de poluição em ambientes urbanos (TUCCI \& MENDES, 2006). Neste sentido, no município também inexiste cadastro da rede pluvial, embora 'bocas-de-lobo' em locais estratégicos coletem as águas pluviais e as conduzam para desaguadouros locais.

Além dos coliformes, bactérias heterotróficas totais foram utilizadas como indicadores complementares da qualidade da água do arroio Clarimundo. As densidades médias de 2,96 $\times$ $10^{3} \mathrm{UFC} / \mathrm{mL}, 6,77 \times 10^{3} \mathrm{UFC} / \mathrm{mL}$ e $1,49 \times 10^{5} \mathrm{UFC} / \mathrm{mL}$ mensuradas no P1, P2 e P3, respectivamente (Tabela 3). Araujo et al. (2015), em avaliação da qualidade da água da Bacia 


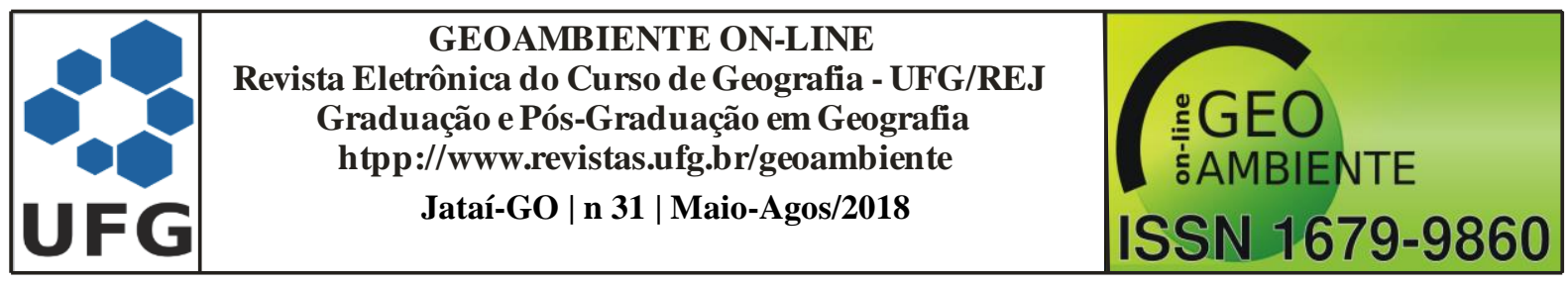

do Córrego Sujo (Teresópolis, RJ), observaram que as contagens médias de bactérias heterotróficas, em oito pontos amostrados, variaram de $1,7 \times 10^{3} \mathrm{UFC} / 100 \mathrm{~mL}$ a $4,7 \times 10^{3}$ UFC/100 mL. Como estas bactérias são parte usual da microbiota aquática, elevações em suas contagens podem indicar aumento da presença de matéria orgânica na água. Esse aporte de matéria orgânica, não necessariamente fecal, pode ter origem no solo, na vegetação do entorno e na descarga de esgotos (ARAUJO et al., 2015).

Tabela 3: Densidade de bactérias heterotróficas totais nas águas do arroio Clarimundo (Cerro Largo/RS) em diferentes coletas realizadas em três pontos de amostragem no ano de 2016.

\begin{tabular}{cccc}
\hline \multirow{2}{*}{ Coleta } & \multicolumn{3}{c}{ Bactérias heterotróficas totais $(\mathbf{U F C} / \mathbf{m L})$} \\
\cline { 2 - 4 } & $\mathrm{P} 1$ & $\mathrm{P} 2$ & $\mathrm{P} 3$ \\
\hline $1^{\mathrm{a}}$ coleta $(29 / 02)$ & $5.700 \mathrm{Ab}$ & $9.900 \mathrm{Ab}$ & $300.000 \mathrm{Aa}$ \\
$2^{\mathrm{a}}$ coleta $(09 / 05)$ & $1.600 \mathrm{Bb}$ & $6.700 \mathrm{ABab}$ & $130.000 \mathrm{ABa}$ \\
$3^{\mathrm{a}}$ coleta $(01 / 08)$ & $2.100 \mathrm{Bb}$ & $4.800 \mathrm{Bb}$ & $91.000 \mathrm{Ba}$ \\
$4^{\mathrm{a}}$ coleta $(07 / 11)$ & $2.450 \mathrm{Bb}$ & $5.700 \mathrm{ABb}$ & $76.000 \mathrm{Ba}$ \\
\hline
\end{tabular}

Médias seguidas pela mesma letra maiúscula em cada coluna, e pela mesma letra minúscula em cada linha, não diferem pelo teste de Tukey $(p>0,05)$.

A Figura 2 apresenta os dados de precipitação diária $(\mathrm{mm})$ e temperatura atmosférica média $\left({ }^{\circ} \mathrm{C}\right)$ durante todo o período das coletas. Elevados índices pluviométricos podem atuar diluindo cargas poluidoras nos corpos d'água (GIATTI et al., 2004; CUNHA et al., 2010; BUZELLI \& CUNHA-SANTINO, 2013). Neste sentido, maiores índices de coliformes fecais em áreas urbanas podem ser detectados em período menos chuvosos (ALVES et al., 2012; FERREIRA \& CUNHA-SANTINO, 2014). Por outro lado, diversos estudos indicam aumento no número de coliformes em corpos d'água durante períodos de maior precipitação (VALLE JUNIOR et al. 2013; SOUZA et al., 2014).

No presente estudo, a análise dos volumes de chuva não indicou, sobremaneira, a aparente vinculação entre precipitações e os parâmetros microbiológicos avaliados. Possíveis exceções podem ser feitas às densidades de coliformes totais, mensuradas durante a $3^{\mathrm{a}}$ e $4^{\mathrm{a}}$ coletas no P1 (Tabela 1), e às densidades totais de coliformes termotolerantes observadas na $3^{\mathrm{a}}$ e $4^{\mathrm{a}}$ coletas nos pontos P1 e P2 (Tabela 2). 


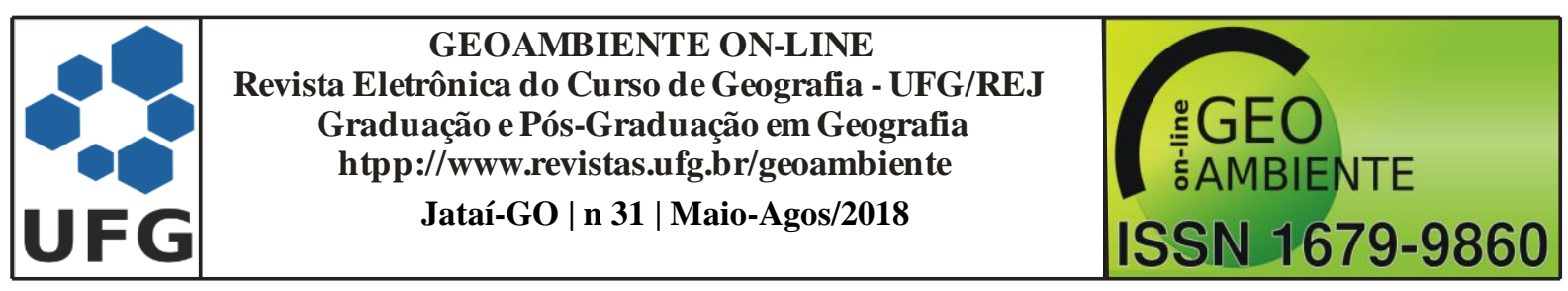

Figura 2: Precipitação diária ( $\mathrm{mm}$; colunas) e temperatura atmosférica média diária $\left({ }^{\circ} \mathrm{C}\right.$; linha) para o município de Cerro Largo/RS, no período de 22 de fevereiro a 08 de novembro de 2016.

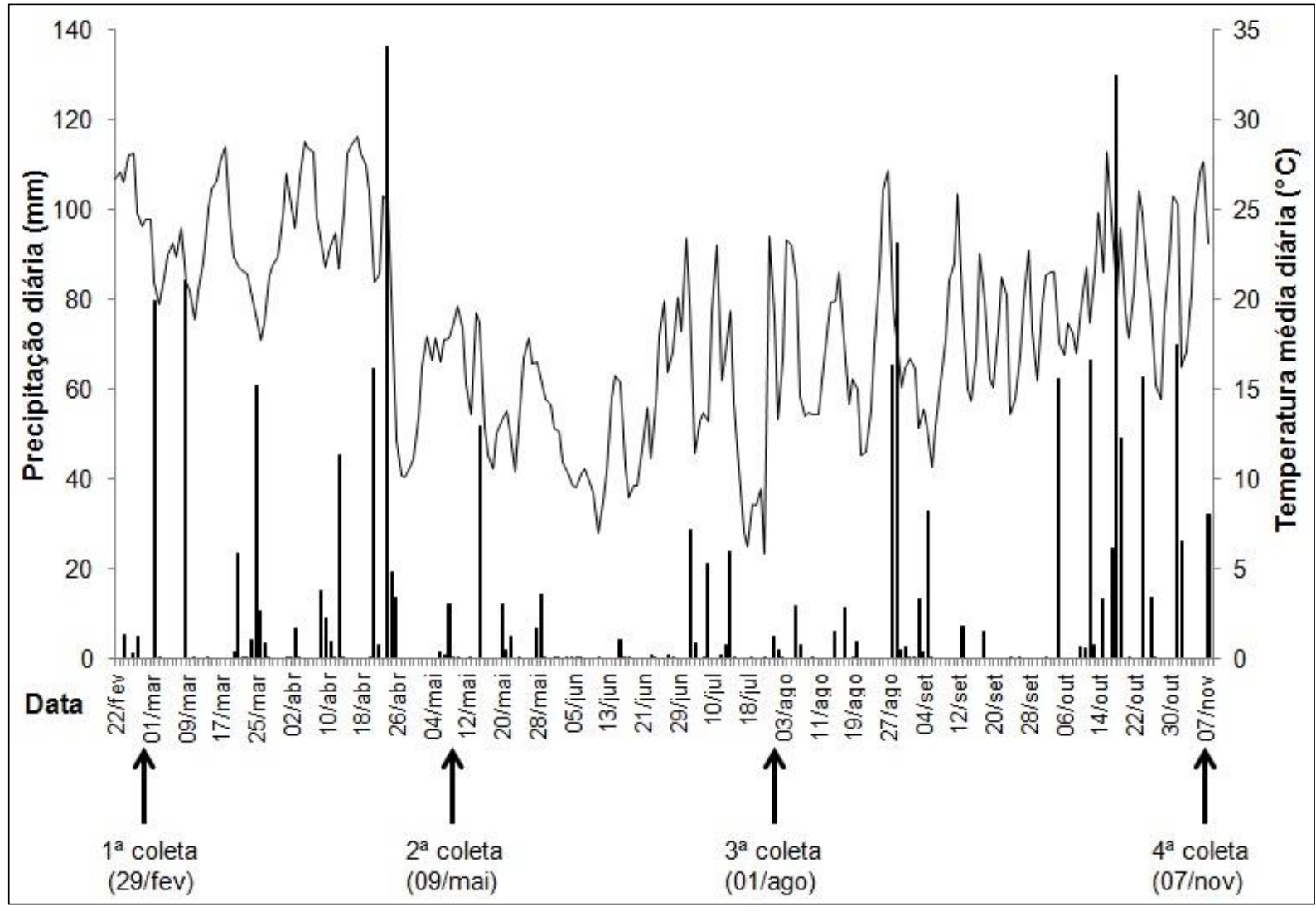

Fonte: estação automática localizada em Cerro Largo/RS.

Nos 30 dias anteriores à $3^{\mathrm{a}}$ e $4^{\mathrm{a}}$ coletas, a precipitação acumulada foi de $87,9 \mathrm{~mm}$ e $526,1 \mathrm{~mm}$, respectivamente; contudo, a precipitação acumulada nos 30 dias anteriores à $1^{\mathrm{a}} \mathrm{e}$ $2^{\mathrm{a}}$ coletas foi de $212,5 \mathrm{~mm}$ e $332,4 \mathrm{~mm}$, respectivamente. Cabe notar, por exemplo, que não foram observados comportamentos análogos para as determinações de coliformes realizadas no P3.

De fato, o efeito de precipitações sobre a qualidade das águas de rios e arroios pode ser relacionado às principais formas de poluição. Segundo Von Sperling (2014), baixos índices de pluviosidade podem concentrar a poluição oriunda de fontes pontuais, enquanto altos índices pluviométricos podem carrear coliformes de fontes difusas de poluição. Sob as perspectivas da ocupação urbana, das condições de escoamento pluvial e com base nas soluções individuais para o esgotamento doméstico, a contaminação detectada pode estar 


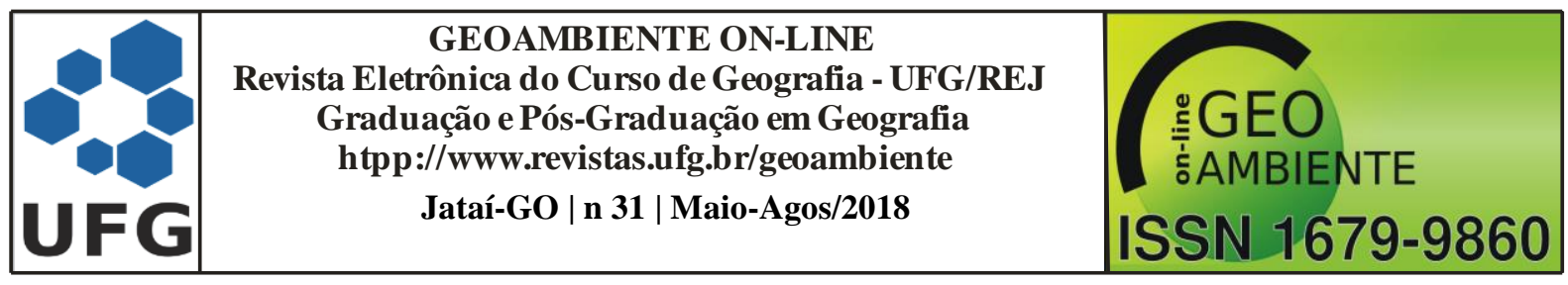

potencialmente relacionada tanto a fontes difusas quanto a fontes pontuais. As fossas sépticas, a estrutura nas canalizações das residências, dejetos carreados por escoamento superficial e mesmo o descarte direto de cargas contaminantes no corpo d'água podem estar contribuindo negativamente à qualidade da água (ALESSIO et al., 2009).

Independentemente da origem da contaminação, tais problemáticas podem resultar em degradação ambiental e da biodiversidade, afetando o funcionamento e manutenção dos ecossistemas, comprometendo os recursos hídricos e, como consequência, a sua utilização (PEREIRA, 2004; MEDEIROS et al., 2009; SOUZA et al., 2014). De maneira importante, alterações na qualidade da água podem comprometer não somente áreas próximas aos impactos, mas também a região circunvizinha em uma bacia hidrográfica (OLIVEIRA FILHO et al., 2012).

Embora este panorama seja detectado com maior intensidade em grandes centros urbanos, pequenas cidades e municípios também vêm sofrendo com a deterioração dos recursos hídricos, especialmente pela descarga de rejeitos e dejetos líquidos e sólidos (NAIME \& FAGUNDES, 2005; VASCONCELLOS et al., 2006; BATISTA \& FUCKS, 2012).

Os coliformes termotolerantes, especialmente, podem apresentar significância na interpretação da qualidade da água, principalmente quando ocorrem variações bruscas em suas densidades na água (VASCO et al., 2010), reforçando a potencial ocorrência de contaminação por efluentes de origem doméstica, e indicando a atenção que os gestores devem dedicar ao saneamento (SIQUEIRA et al., 2012).

\section{Considerações finais}

O arroio Clarimundo, mesmo considerando sua curta extensão e a pequena área urbana que perpassa, aparentemente sofre influência de dejetos de origem doméstica. Após perpassar a área urbana de Cerro Largo (P3), as águas do referido arroio corresponderam àquelas de Classe 4 conforme a classificação apresentada na Resolução CONAMA 357/05. Nos pontos P1 e P2, à montante do P3, as águas do arroio Clarimundo apresentaram melhor qualidade microbiológica. 


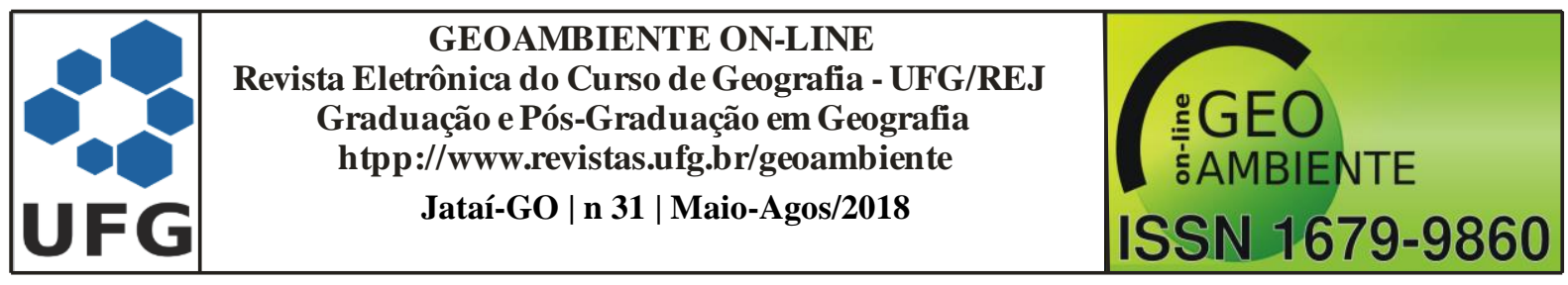

Esta investigação corrobora que as preocupações referentes à qualidade dos recursos hídricos em áreas urbanas são, pelo menos em parte, reflexo de situações similares que se repetem em diferentes locais. Há, portanto, a necessidade de reverter estes cenários, buscando promover melhorias que serão potencialmente percebidas tanto no contexto ambiental quanto na perspectiva da qualidade de vida da população.

\section{Referências}

ALESSIO, C. E.; PINTO, F. G. S.; MOURA, A. C. Avaliação microbiológica das águas das principais fontes de praças e parques de Cascavel - PR. UNOPAR Científica. Ciências Biológicas e da Saúde, v. 11, n. 2, p. 41-44, 2009.

ALVES, I. C. C.; El-ROBRINI, M.; SANTOS, M. L. SS.; MONTEIRO, S. M.; BARBOSA, L. P. F.; GUIMARÃES, J. T. F. Qualidade das águas superficiais e avaliação do estado trófico do Rio Arari (Ilha de Marajó, norte do Brasil). Acta Amazonica, v. 42, n. 1, p. 115-124, 2012.

ANDRADE, A. R.; FELCHAK, I. M. A poluição urbana e o impacto na qualidade da água do rio das Antas - Irati/PR. Geoambiente On-Line, n. 12, p. 108-132, 2009.

ANDRADE, S. O.; CRISPIM, D. L.; SOUZA, M. A.; CHAVES, A. D. C. G.; MARACAJÁ, P. B. Análise espacial da qualidade microbiológica das águas do rio Piancó no trecho Coremas-Pombal-PB. Revista Verde de Agroecologia e Desenvolvimento Sustentável, v. 10, n. 12, p. 157-161, 2015.

ARAUJO, F. V.; VIEIRA, L.; JAYME, M. M. A.; NUNES, M. C.; CORTÊS, M. Avaliação da qualidade da água utilizada para irrigação na bacia do Córrego Sujo, Teresópolis, RJ. Cadernos de Saúde Coletiva, v. 23, n. 4, p. 380-385, 2015.

BATISTA, B. G.; FUCKS, M. B. Avaliação microbiológica da água do Arroio Pessegueirinho de Santa Rosa, noroeste do Estado do Rio Grande do Sul. Monografias Ambientais, v. 9, n. 9, p. 2031-2037, 2012.

BLODGETT, R. Most Probable Number from serial dilutions (Appendix 2). In: United States Food and Drug Administration (FDA). Bacteriological Analytical Manual (BAM). Silver Spring: $2010 . \quad$ DDA, Disponível em: 


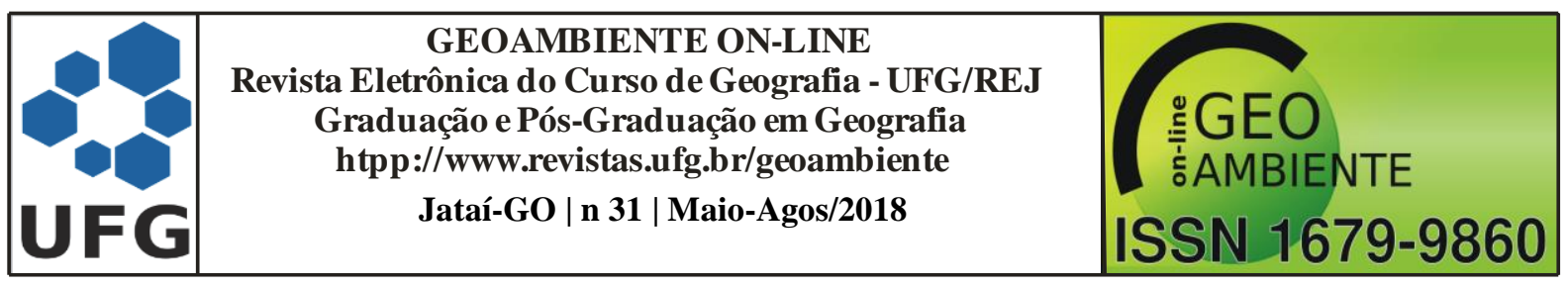

<http://www.fda.gov/Food/FoodScienceResearch/LaboratoryMethods/ucm109656.htm>. Acesso em: 12 mar. 2017.

BRASIL. Ministério do Meio Ambiente. Conselho Nacional do Meio Ambiente. Resolução ${ }^{\circ}$ 274, de 29 de novembro de 2000. Diário Oficial da União, nº 018, Brasília, DF, Seção 1, 08 de janeiro de 2001, p. 70-71.

BRASIL. Ministério do Meio Ambiente. Conselho Nacional do Meio Ambiente. Resolução $n^{\circ}$ 357, de 17 de março de 2005. Diário Oficial da União, nº 053, Brasília, DF, Seção 1, 18 de março de 2005, p. 58-63.

BRASIL. Ministério do Meio Ambiente (MMA). Plano Nacional de Recursos Hídricos. Panorama e estado dos recursos hídricos do Brasil. Volume 1. Brasília: MMA, 2006.

BRASIL. Ministério das Cidades. Secretaria Nacional de Saneamento Ambiental (SNSA).

Sistema Nacional de Informações sobre Saneamento: diagnóstico dos serviços de água e esgotos - 2015. Brasília: SNSA/MCIDADES, 2017.

BUZELLI, G. M.; CUNHA-SANTINO, M. B. Análise e diagnóstico da qualidade da água e estado trófico do reservatório de Barra Bonita, SP. Ambi-Água, v. 8, n. 1, p. 186-205, 2013.

CUNHA, A. H.; TARTLER, N.; SANTOS, R. B.; FORTUNA, J. L. Análise microbiológica da água do rio Itanhém em Teixeira de Freitas-BA. Revista Biociências, v. 16, n. 2, p. 86-93, 2010.

DIEL, M. I.; PORTELA, V. O.; CHASSOT, T.; SANTOS, M. T. P. Fitossociologia do componente arbóreo do entorno da nascente no Arroio Clarimundo, afluente do Rio Ijuí - Rio Grande do Sul, Brasil. Agrarian Academy, v. 2, n. 4, p. 21-31, 2015.

FERREIRA, C. S.; CUNHA-SANTINO, M. B. Monitoramento da qualidade da água do rio Monjolinho: a limnologia como uma ferramenta para a gestão ambiental. Revista de Estudos Ambientais, v. 16, n. 1, p. 27-37, 2014.

GIATTI, L. L.; ROCHA, A. A.; SANTOS, F. A.; BITENCOURT, S. C.; PIERONI, S. R. M. Condições de saneamento básico em Iporanga, Estado de São Paulo. Revista de Saúde Pública, v. 38, n. 4, p. 571-577, 2004.

GOOGLE MAPS. Cerro Largo - RS, Brasil. Disponível em: < https://www.google.com.br/maps/place/Cerro+Largo+-+RS/@-28.1379598,- 


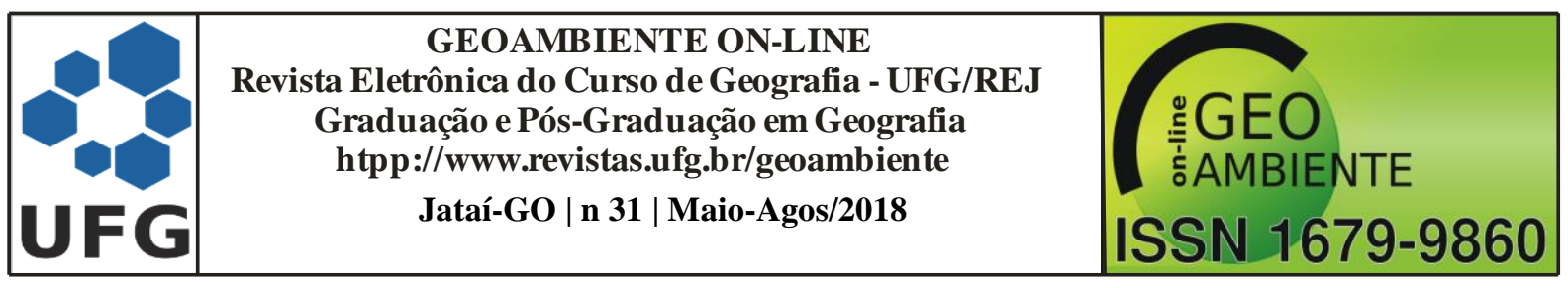

54.8613944,11z/data=!3m1!4b1!4m5!3m4!1s0x94fed70ba9535bbd:0xbc58fc314f726092!8m 2!3d-28.1437464!4d-54.7192376>. Acesso em: 15 jan. 2018.

INSTITUTO BRASILEIRO DE GEOGRAFIA E ESTATÍSTICA (IBGE). IBGE Cidades Rio Grande do Sul - Cerro Largo. Disponível em: < http://www.cidades.ibge.gov.br/xtras/perfil.php?lang=\&codmun=430520\&search=rio-grandedo-sul|cerro-largo>. Acesso em: 12 mai. 2017.

MAROTTA, H.; SANTOS, R. O.; ENRICH-PRAST, A. Monitoramento limnológico: um instrumento para a conservação dos recursos hídricos no planejamento e na gestão urbanoambientais. Ambiente \& Sociedade, v. 11, n. 1, p. 67-79, 2008.

MEDEIROS, G. A.; ARCHANJO, P.; SIMIONATO, R.; REIS, F. A. G. V. Diagnóstico da qualidade da água na microbacia do córrego Recanto, em Americana, no Estado de São Paulo.

Geociências, v. 28, n. 2, p. 181-191, 2009.

NAIME, R.; FAGUNDES, R. S. Controle da qualidade da água do Arroio Portão - Portão, RS. Pesquisas em Geociências, v. 32, n. 1, p. 27-35, 2005.

OLIVEIRA FILHO, P. C.; DUTRA, A. M.; CERUTI, F. C. Qualidade das águas superficiais e o uso da terra: estudo de caso pontual em bacia hidrográfica do oeste do Paraná. Floresta e Ambiente, v. 19, n. 1, p. 32-43, 2012.

PEREIRA, R. S. Poluição hídrica: causas e consequências. Revista Eletrônica de Recursos Hídricos, v. 1, n. 1, p. 20-36, 2004.

RAZZOLINI, M. T. P.; GUNTHER, W. M. R. Impactos na saúde das deficiências de acesso a água. Saúde e Sociedade, v. 17, n. 1, p. 21-32, 2008.

ROCHA, J. L. S.; REGO, N. A. C.; SANTOS, J. W. B.; OLIVEIRA, R. M.; MENEZES, M. Indicador integrado de qualidade ambiental aplicado à gestão da bacia hidrográfica do rio Jiquiriçá, BA, Brasil. Ambi-Água, v. 5, n. 1, p. 89-101, 2010.

SAlVATORI, R. U.; WOLF, G. A. K; DRESCH, F.; STROHSCHOEN, A. A. G. Laboratório de Microbiologia: normas gerais, instruções de trabalho e procedimentos operacionais padrões. Lajeado: Editora da Univates, 2013.

RIO GRANDE DO SUL. Secretaria Estadual do Meio Ambiente - SEMA. Relatório anual sobre a situação dos recursos hídricos no Estado do Rio Grande do Sul - Ano 2009/2010. Porto Alegre: SEMA, 2012a. 


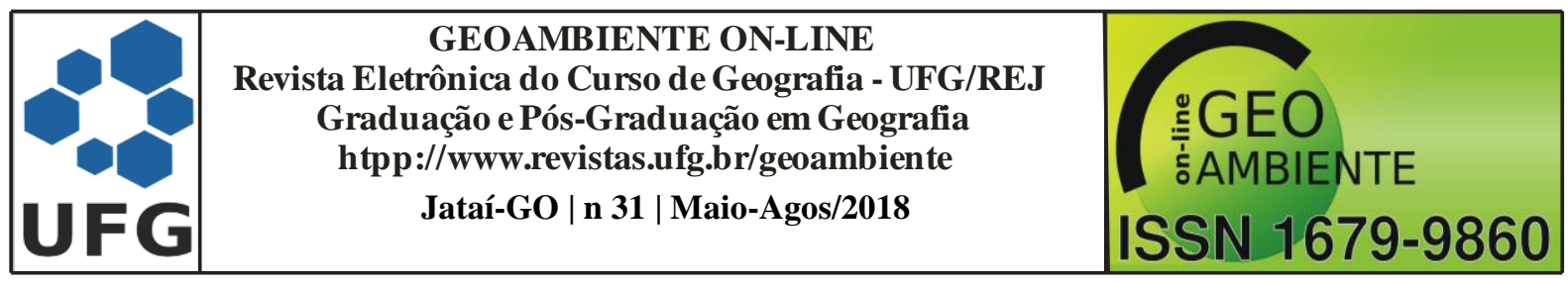

RIO GRANDE DO SUL. Secretaria Estadual do Meio Ambiente - SEMA. Processo de planejamento dos usos da água na Bacia Hidrográfica do Rio Ijuí: enquadramento. Porto Alegre: SEMA, 2012b.

SIQUEIRA, G. W.; APRILE, F.; MIGUÉIS, A. M. Diagnóstico da qualidade da água do rio Parauapebas (Pará - Brasil). Acta Amazônica, v. 42, n. 3, p. 413-422, 2012.

SOUZA, J. R.; MORAES, M. E. B.; SONODA, S. L.; SANTOS, H. C. R. G. A importância da qualidade da água e os seus múltiplos usos: caso rio Almada, Sul da Bahia, Brasil. REDE Revista Eletrônica do Prodema, v. 8, n. 1, p. 26-45, 2014.

TUCCI, C. E. M; MENDES, C. A. Avaliação ambiental integrada de bacia hidrográfica. Brasília: Ministério do Meio Ambiente, 2006.

TUNDISI, J. G. (Coord.) Recursos hídricos no Brasil: problemas, desafios e estratégias para o futuro recursos hídricos. Rio de Janeiro: Academia Brasileira de Ciências, 2014.

VALLE JUNIOR, R. F.; ABDALA, V. L.; GUIDOLINI, J. F.; SIQUEIRA, H. E.; CANDIDO, H. G. Diagnóstico temporal e espacial da qualidade das águas superficiais do rio Uberaba - MG. Caminhos de Geografia, v. 14, n. 45, 11 pp., 2013.

VASCO, A. N.; MELlO JÚNIOR, A. V.; SANTOS, A. C. A. S.; RIBEIRO, D. O.; TAVARES, E. D.; NOGUEIRA, L. C. Qualidade da água que entra no estuário do rio Vaza Barris pelo principal fluxo de contribuição de água doce. Scientia Plena, v. 6, n. 10, 10 pp., 2010.

VASCONCELLOS, F. C. S.; IGANCI, J. R. V.; RIBEIRO, G. A. Qualidade microbiológica da água do Rio São Lourenço, São Lourenço do Sul, Rio Grande do Sul. Arquivos do Instituto Biológico, v. 73, n. 2, p. 177-181, 2006.

VON SPERLING, M. Introdução à qualidade das águas e ao tratamento de esgotos. 4. ed. Belo Horizonte: Editora UFMG, 2014. 